Accepted version of

Vilar, R., Liu, J. H., Coelho, G. L. H., Hanel, P. H. P., Araújo, R. C. R., Monteiro, R. P., \& Gouveia, V. V. (2021). On the road: Personality and values of sojourners. Current Psychology.

\title{
On the road: Personality and values of sojourners
}

Roosevelt Vilar ${ }^{1}$, James H. Liu ${ }^{1}$, Gabriel L. H. Coelho², Paul H. P. Hanel ${ }^{3}$, Rafaella C. R. Araújo $^{1}$, Renan P. Monteiro ${ }^{4}$, Valdiney V. Gouveia ${ }^{5}$

${ }^{1}$ Massey University, New Zealand

${ }^{1}$ University College Cork, Ireland

${ }^{3}$ University of Essex, United Kingdom

${ }^{4}$ Universidade Federal de Mato Grosso, Brazil

${ }^{5}$ Universidade Federal da Paraíba, Brazil

\section{Author Biographies}

Roosevelt Vilar is a PhD candidate at the School of Psychology, Massey University, New Zealand

James H. Liu is a Professor and Head of School at the School of Psychology, Massey University, New Zealand

Gabriel L. H. Coelho is a Postdoctoral Researcher at the School of Psychology, University College Cork, Ireland

Paul H. P. Hanel is a Lecturer at the Department of Psychology, University of Essex, Essex, UK

Rafaella C. R. Araújo is a Postdoctoral Researcher at the School of Psychology, Massey University, New Zealand

Renan P. Monteiro is a Lecturer at the Departamento de Psicologia, Universidade Federal Do Mato Grosso, Brazil

Valdiney V. Gouveia is a Professor at the Departamento de Psicologia, Universidade Federal da Paraíba, Brazil

Direct correspondence to:

Roosevelt Vilar

School of Psychology, Massey University, Auckland 0632, New Zealand.

Roosevelt.vilar@gmail.com 


\title{
On the road: Personality and values of sojourners
}

\begin{abstract}
We investigated differences in personality traits (Big-5) and human values amongst four groups of Brazilian students staying at home or studying abroad. Two groups came from Brazilian universities: one had no interest studying abroad $(n=112)$, while the other group was interested studying abroad $(\mathrm{n}=227)$. The third and fourth groups were Brazilian sojourners $(\mathrm{n}=121)$ and Brazilians returning to the country after finishing a degree abroad $(\mathrm{n}$ $=150$ ). Results showed that students who were not interested in studying abroad had lower scores on excitement values and on the personality trait of openness when compared to the other three groups. Overall, students interested in studying abroad did not differ significantly from sojourners or returnees, except on the trait of agreeableness and the value of excitement, in which they scored lower than sojourners and returnees, respectively.
\end{abstract}

Keywords: International mobility; sojourners; values; personality traits. 


\section{Introduction}

Many students around the world seek to experience different cultures, for various reasons. For example, they might look for opportunities to improve their skills, learn a new language, or want to understand how people in another culture live. In contrast, other students might wish to stay closer to their families and friends, and therefore prefer not to go abroad. To better understand this intention to live abroad, it is important to explore the role of personality traits and human values, which are central constructs to understand the formation of attitudes and behaviors (Araujo et al., 2020; Gallego \& Pardos-Prado, 2013; Maio, 2016; Parks \& Guay, 2009). Such findings can help to develop "study abroad” programs (e.g., ERASMUS, Science without Borders) and support strategies to help sojourners to adapt overseas, which might be especially relevant when there is a high economic and cultural distance between the country of origin and the host country (Alharbi \& Smith, 2018; Basow \& Gaugler, 2017; Szabo, Ward, \& Jose, 2016). To achieve this, in the present research we compare sojourners abroad and stay home university students in terms of the Big-Five Personality Theory (McCrae \& Costa, 1997) and the Functional Theory of Human Values (Gouveia, Milfont, \& Guerra, 2014).

\section{Personality Traits, Human Values, and Sojourning}

Studies investigating the differences between sojourners and those who do not go abroad often focused on personality traits (e.g., Big-5). Researchers argued that there is a migrant personality that is characterized by willingness to experience new situations (Campbell, 2019; Jokela, 2009; Jokela, 2014; Tabor, Milfont, \& Ward, 2015). This willingness to change one's lives and start again somewhere else is characterized by high openness and extraversion scores. These two traits are also related with the motivation to study abroad: students who intent to go abroad or who are abroad score higher on openness and extraversion than students who do not share this interested (self-selection effect; Bakalis 
\& Joiner, 2004; Niehoff, Petersdotter, \& Freund, 2017; Richter, Zimmermann, Neyer, \& Kandler, 2020; Zimmermann \& Neyer, 2013). Differences on agreeableness and conscientiousness are less consistency. Additional to self-selection effects, being abroad increases agreeableness and emotional stability (Niehoff et al., 2017; Zimmermann \& Neyer, 2013).

On the other hand, studies examining differences in value orientations between sojourners and stay at homers are scarce (see Bardi, Buchanan, Goodwin, Slabu, \& Robinson, 2014; Rudnev, 2014; Tartakovsky, Walsh, Patrakov, \& Nikulina, 2017). Bardi et al.’s (2014) research on Polish immigrants is the most relevant for our study, because the authors used data from people who had just moved from Poland to the United Kingdom. The results showed that Polish migrants scored higher on self-direction and stimulation when compared to their fellow countrymen and -women, but lower on tradition, conformity, security and power values. These results were in line with research on the motivations for emigration (Tartakovsky \& Schwartz, 2001).

Personality traits and values are correlated and conceptually similar, but recent research has highlighted important differences that make these two constructs independent from each other (e.g., Hanel \& Maio, 2020; Parks-Leduc, Feldman, \& Bardi, 2015). One of the most basic differences is that traits refer to a description of the individual, whereas values are related to motivation. For instance, openness in the context of traits describes how open the individual sees themselves across situations, whereas in the context of values openness refers to the importance the individual attributes to be open and independent. In this case, although openness' behavior (trait) and motivation (values) are similar and highly correlated (Parks-Leduc et al., 2015; Roccas, Sagiv, Schwarts, \& Knafo, 2002), values might explain variance beyond traits on interest to sojourn because values are better predictors of temporal more distant behavior (Eyal et al., 2009) and sojourning typically includes a commitment of 
one to several years. Further, values explained variance beyond traits in leadership aspirations (Lechner, Sortheix, Obschonka, \& Salmela-Aro, 2018), which is also future oriented.

\section{Study Overview and Hypothesis}

Overall, our study aims to examine the role of traits and values on intentions to sojourn. This study is especially relevant for the value literature, as there are only a few studies including this set of constructs to explain the interest to sojourn. In addition, we assess students with different intentions when it comes to study abroad, which might hint whether differences in sojourning are based on self-selection or socialization effects. For instance, differences between students with no interest to study abroad (no sojourner motivation) and students interested to study abroad, sojourners, and returnees (sojourner motivation) might suggest a self-selection effect because there is a clear distinction of sojourning motivation between the groups. Further, differences between students interested to study abroad on one hand and sojourners and especially returnees on the other hand might hint at socialization effects. Of importance, our sample is from a non-WEIRD (Western, Educated, Industrialized, Rich, and Democratic; Henrich, Heine, \& Norenzanya, 2010) context, which contributes to the field by testing to what extent main findings on the relations between traits and interests to sojourn can be generalized.

We operationalize traits and values using the Big-Five Personality Theory (McCrae \& Costa, 1997) and the Functional Theory of Human Values (Gouveia, Milfont, \& Guerra, 2014). The Big-5 model consists of agreeableness, conscientiousness, extraversion, neuroticism or emotional stability, and openness to new experiences. The Functional Theory consists of six dimensions of values that have different cognitive functions (see Gouveia et al., 2014). To summarize, (1) interactive values assist interpersonal relations (e.g., belonging),

(2) normative values are related to behavioral regulation by social norms (e.g., tradition), (3) suprapersonal values express higher order thoughts (e.g., maturity), (4) existence values 
represent basic needs (e.g., health), (5) excitement values express personal desires (e.g., pleasure), and (6) promotion values are closely related to the importance of career progress (e.g., success; Gouveia et al., 2014a). There is a substantial overlap between Gouveia's (2003) and Schwartz's (1992) value models that allow us to draw upon research that used Schwartz model to derive our hypotheses. For example, normative values overlap with Schwartz's tradition and conformity values, promotion values with achievement and power, and excitement values with hedonism and stimulation (for similarities between models see Gouveia et al., 2014b and Hanel, Litzellachner, \& Maio, 2018).

According to Jokela (2014), residential mobility starts with a desire to move, which leads to an intention and expectation to move, that finally materializes on the actual act of moving. Further, both Jokela (2014) and Campbell (2019) showed that traits associated with desires and intentions to migrate also predict migration outcomes. In this case, our design provides insights into how a general desire or interest to study abroad (as opposed to a more focused intention or plan to go abroad) might be associated with a sojourner mentality in terms of personality and values. Therefore, we expect that:

Hypothesis 1. People interested in studying abroad, sojourners, and returnees will score higher on the traits of extraversion and openness compared to individuals who do not have the interest to study abroad.

Hypothesis 2. People interested in studying abroad, sojourners, and returnees, will place higher priority on excitement and suprapersonal values compared to individuals who do not have the interest to study abroad.

Hypothesis 3. People interested in studying abroad, sojourners, and returnees, will give lower priority to existence, normative and promotion values compared to individuals who are not interested in studying abroad. 
The four groups we included in our sample differed in their sojourner motivation (interested in studying abroad vs not interested) and sojourning experiences (still being abroad vs already returned). If groups without sojourning experiences are different from those who are having or have had a sojourner experience, regardless of their motivations to have an overseas experience, this could suggest a socialization effect. This is because there would be a clear difference on experience but not on intentions, since there is a group without sojourning experience but with intention to sojourn. For personality traits, Zimmermann and Neyer (2013) and Niehoff et al. (2017) reported an increase on agreeableness and emotional stability with the overseas experience. Regarding socialization effects for values, Bardi et al. (2014) reported effects only for self-direction and power. Based on this literature, we hypothesize differences between groups regarding their sojourning experiences only for agreeableness and emotional stability, which should be higher for individuals who are studying or have studied abroad.

Hypothesis 4. Sojourners and returnees (individuals with experience abroad) will have higher scores on agreeableness and emotional stability than individuals who do not have the interest to study abroad and individuals who have the interest to study abroad (individuals with no experience abroad).

\section{Method}

\section{Participants and Procedure}

The full sample consisted of 610 Brazilians $\left(M_{a g e}=23.90, S D=4.98 ; 61.3 \%\right.$ female $)$. The first group consisted of undergraduate and postgraduate students who are taking their degree in Brazil and reported no interest to study abroad $\left(n=112 ; M_{a g e}=24.6, S D=6.50\right.$; $57.7 \%$ female). The second group consisted of undergraduate and postgraduate students who are taking their degree in Brazil and reported interest to study abroad $\left(n=227 ; M_{\text {age }}=22.5\right.$, $S D=4.58 ; 59.9 \%$ female $)$. The third group consisted of sojourner students $\left(n=121 ; M_{\text {age }}=\right.$ 
$24.2, S D=3.45 ; 60.3 \%$ female) who were abroad when they completed the survey, predominantly staying between 6 months and 1 year (74.7\%). Finally, the fourth group consisted of returnees $\left(n=150 ; M_{a g e}=25.4, S D=4.61 ; 61.2 \%\right.$ female $)$ who had between 6 months and 1 year (56.5\%) of experience abroad or between 1 and 2 years $(30.5 \%)$. For this last group, participants who lived abroad between 6 to 12 months were different from participants who lived abroad between 1 and 2 years only for promotion values, $t(148)=2.26$, $p=.025$, with participants who lived abroad between 6-12 months scoring higher/lower compared to those who lived abroad between 1-2 years. Otherwise, these participants showed fairly similar scores overall, so we grouped them together. The majority of sojourners and returnees were living or had lived in English speaking countries (58.3\%; e.g., United States, United Kingdom, Canada, Australia) or countries with a Latin cultural background (28.3\%; e.g., Portugal, Spain, France, Italy). The remaining 13.4\% were living or had lived in other European countries (e.g., Germany, Hungary, Belgium, Sweden). To see whether the potential cultural proximity of Brazilians with other Latin cultures would influence mean comparisons, we performed a MANOVA using these three groups of countries as the fixed factor, and values and traits as dependent variables. As results showed no significant differences between groups, we decided not to differentiate participants based on the location of their oversea studies [Wilks's $\lambda=.94, F(22,468)=0.67, p=.87, \eta_{\mathrm{p}}^{2}=.03$ ]. We examined skewness for each variable. Results were between -.979 (interactive) and .077 (neuroticism) $(M=-.344, S D$ $=.340$ ), suggesting that none of the variables was highly skewed.

Participants were contacted through Facebook groups of Brazilian universities, or groups created by sojourners living abroad. We joined these groups and posted a link inviting members of these groups to complete the survey. No reward was given for participation.

\section{Material}


Basic Values Survey (BVS; Gouveia, 2003): This scale measures the 6 dimensions of human values of the Functional Theory (Gouveia, 2013) with in total 18 values/items. Respondents rated how important each of the values was to them on a scale ranging from 1 (Completely unimportant) to 7 (Of the utmost importance). Alpha coefficients for the full sample ranged from .47 (existence) to .69 (normative) $\left(\alpha_{\text {mean }}=.57\right)$, and are comparable to those found in previous research (Gouveia et al., 2014). Alphas for each group are reported in Table A1 of the supplementary materials.

Ten-item Personality Inventory (TIPI; Gosling, Rentfrow, \& Swann, 2003): This measure is composed of 10 items assessing each one of the BIG-5 personality dimensions. Participants rated the items on a scale ranging from 1 (strongly disagree) to 7 (strongly agree). Pearson correlations were positive and significant between the two items forming each of the personality dimensions, except for agreeableness, where correlations between the two items in all four groups were low (see Table S2 in the supplementary materials). Note that the measure was created to capture each of the five broad dimensions with two items and not to result in high internal consistencies (Gosling, n.d.).

\section{Data Analysis}

MANOVAs were conducted to examine whether groups were different in terms of personality or values. Post-hoc comparisons were performed using Bonferroni correction. Analyses were conducted using SPSS (version 25).

\section{Results}

\section{[Table 1 around here]}

Descriptive statistics, correlations, and reliabilities for each of the four groups are reported as supplementary materials.

A MANCOVA including values and personality traits as dependent variables, and age and gender as covariates, was performed to examine differences amongst the four groups. Age 
and gender were used to control the analysis by possible cofounding effects, since traits and values vary in function of these two demographic variables (Costa Jr., Terraciano, \& McCrae, 2001; Milfont, Milojev, \& Sibley, 2016). Our results showed that there are overall differences in values and traits across the four groups, Wilks's $\lambda=.85, F(33,1668)=2.78, p<.001, \eta_{\mathrm{p}}{ }^{2}$ $=.05$. Table 1 shows ANCOVAs for each value and each trait. There were significant differences between groups regarding excitement and existence values, and the traits of extraversion, agreeableness, and openness. Effect sizes for excitement values and the trait of agreeableness were small to medium, and small for existence values and the traits of extraversion and openness. The hypothesized differences for normative and suprapersonal value subfunctions were not significant.

Table 2 shows post-hoc (Bonferroni corrected) differences between groups. Starting with traits, post-hoc comparisons revealed that students who did not have interest to study abroad scored lower on the traits of openness and extraversion compared to the other groups, supporting Hypothesis 1. Effect sizes were larger than .30 (small to medium) for the comparisons between students not keen to go abroad, and the two groups of sojourners in the traits of openness and extraversion. When comparing students not keen and keen to study abroad, we found smaller effect sizes. Effects were significant for the trait of openness, but not extraversion. Nevertheless, results were in the expected direction for extraversion. These findings follow the hypothesized direction, but only openness fully confirmed Hypothesis 1 in terms of significance. We also found significant differences for agreeableness between sojourners and the two groups of stay home students, with effect sizes close to .50 (medium). This finding goes in line with Hypothesis 4 for agreeableness, but it was not fully confirmed because returnees were not statistically different from stay home students. However, results were again in the expected direction. The five variables which means differed significantly between groups are displayed in Figure 1. 


\section{[Figure 1 around here]}

Regarding human values, post-hoc comparisons showed that students not keen to study abroad scored lower on excitement values than sojourners and returnees. The difference between students not keen to study abroad and sojourners was only marginally significant ( $p$ $=.064)$ for excitement values, but the effect size for this comparison was similar to the effects found for extraversion and openness. Even though the later trait was the only one to register significant differences, the similarity in effect sizes suggest their importance to differentiate students without interest to go abroad and students who are interested in sojourning or students that are having a sojourner experience. Results also showed that students not interested in study abroad placed more importance to existence values than sojourners. These findings are in line with Hypotheses 2 and 3, but results were not fully confirmed in terms of significance testing.

Finally, we tested whether traits and values would still differentiate the groups after they were controlled for by one another. These analyses were performed because traits and values are correlated constructs (Parks-Leduc et al., 2015), but are still conceptually different as we outlined above. When including values, age and gender as covariates, only the differences reported for agreeableness remained significant, $\left[F(3,570)=4.74 ; p=.003 ; \eta^{2} \mathrm{p}=\right.$ .02]. On the other hand, when we included personality, age, and gender as covariates for values, results remained significant for excitement $\left[F(3,571)=5.20 ; p=.002 ; \eta^{2}{ }_{p}=.03\right]$ and existence values $\left[F(3,571)=2.67 ; p=.047 ; \eta^{2} \mathrm{p}=.03\right]$; normative values also became significant, $\left[F(3,571)=3.30 ; p=.020 ; \eta^{2} \mathrm{p}=.02\right]$. Details of the post hoc differences in traits and values after controlling for the effects of each other are available in the supplementary materials.

[Table 2 around here]

\section{General Discussion}


In the present study, we compared differences in personality traits and human values of students who did not go abroad and did not have the interest to do so, students who also did not go abroad, but had the interest to go, sojourners, and returnees. Comparisons between these groups contribute to a better understanding of whether there is a "sojourner mentality". Specifically, whether people who are interested to go abroad have similar values and traits compared with people who are abroad or have returned from an international experience. We found that students interested in sojourning did not show significant differences when compared with the two groups of sojourners, except for having lower excitement values when compared to returnees, and lower agreeableness than current sojourners. These results are coherent with the idea that there is a good chance that sojourners are already high in openness and excitement before going abroad (i.e., self-selection effects; Bardi et al., 2014; Neihoff et al., 2017; Zimmermann \& Neyer, 2013). Indeed, Bardi et al. (2014) found that excitement/stimulation values are pivotal to lead people to embark on a change of residence, culture, and language. In addition, Tabor et al. (2015) and Jokela (2009) indicated that openness and extraversion are the main personality traits held by people intending to migrate. Regarding agreeableness, we found that sojourners were higher on this trait rather than participants studying in their home countries, either with or without interest in study abroad (with current sojourners scoring highest). This result is consistent with findings reported by Zimmermann and Neyer (2013), who showed that agreeableness increases over time with socialization abroad.

Additional to the "sojourner mentality" related to the willingness to experience new situations (excitement values and the traits of openness and extraversion) and disposition to enhance social contacts (agreeableness), we found that existence values differentiated students not keen to study abroad and actual sojourners. This finding is in line with results reported by Bardi et al. (2014): placing higher importance to stability and safety can be one of the reasons 
why people who endorse conservation values are less likely to move abroad. The higher scores on existence values for students without interest in study abroad compared to students interested in study abroad were in the same direction and had almost the same effect size as the difference between the former and sojourners. These results support the claim that people who are more pragmatically oriented are also less likely to have or want sojourner experience.

When we tested whether traits would still differentiate between the four groups when we controlled for values and vice versa, the only trait that remained significant was agreeableness. In contrast, we found significant differences for excitement, existence, and normative values. This implies that abstract ideals (values) are more relevant in far reaching decisions such as going abroad than how a person currently describes herself (traits; cf. Hanel \& Maio, 2020). However, these comparisons need to be further evaluated since our measure of openness, which is a key construct in the sojourner literature, did not present equality of variance between the groups considered in the present research (Levene's test was significant).

Our findings support previous research showing that there is a self-selection effect between people who are interested to sojourn and those who are not (Jokela, 2009; Tabor et al., 2015; Zimmermann, Schubert, Bruder, \& Hagemeyer, 2017). As the interest to move abroad starts much earlier in one's life than the actual plans or actions to move (Jokela, 2014; Yijälä \& Jasinskaja-Lahti, 2010), knowing the differences between groups with and without such interests is an important aspect to be considered.

Our findings are in line with Gouveia (2003) theory of values that describes openminded/risk-taking people as more willing to accept personal and social change. It may be that sojourners have an "open and social" disposition in terms of personality and values, particularly valuable in the adaptation process (Zimmermann et al., 2017). Sojourners appear to have higher scores on a number of positive qualities around openness regardless of the 
context where they come from (Bardi et al, 2014; Niehoff et al, 2017; Tabor et al., 2015; Zimmermann \& Neyer, 2013) or the context they travel to. For instance, we did not find significant mean differences between students who had their sojourning experiences in English speaking countries or countries with a Latin background. These findings suggest that mean differences are more related to the act of sojourning than cultural influence (e.g., Geeraert et al., 2019), but more research is needed to assess the influence of the host culture.

Although most of the findings were in the expected direction, comparisons between groups regarding suprapersonal and normative values were not significant (cf. Hypotheses 2 and 3). As suprapersonal values represent attributes that can facilitate embarking in an overseas experience, such as being open, valuing freedom and having cosmopolitan characteristics (Cleveland, Endorgan, Arikan, \& Poyraz, 2011), we hypothesized these values would be more salient for groups that reported an intention to sojourn. Suprapersonal values are also significantly related to the trait of openness to experiences (Parks-Leduc, Feldman, \& Bardi, 2015), which have shown to be an important construct at predicting sojourning intentions or behaviours (Campbell, 2019; Jokela, 2009; Jokela, 2014; Tabor, Milfont, \& Ward, 2015). However, our findings did not support the hypothesis examining differences between groups on suprapersonal values. In fact, universalism/suprapersonal values are positively related to cosmopolitanism but negatively related to travelling (Cleveland et al., 2011). Also, in Bardi's et al.'s (2014) study, universalism values were not relevant to differentiate Polish migrants to Polish people staying home. These results might suggest that valuing acceptance and having a positive approach toward other cultures does not necessarily mean one will be inclined to travel and experience a new culture.

Contrary to our predictions, we also did not find significant differences for normative values (Hypothesis 3). Normative values tend to represent people who are less open to new experiences and linked to ingroup favoritism. For instance, normative values are related to 
traditional ingroup and local geospatial identification (Gouveia, Albuquerque, Clemente, \& Espinoza, 2010). Also, research from Bardi et al. (2014) showed that Polish residents scored higher in normative values than Polish migrants. These finds led us to hypothesize that people not interested in sojourning would show higher scores in normative values than people that were interested in this experience. However, our findings did not support this hypothesis. We speculate that the characteristic of the sample might be playing a role in the results since university students tend to be less guided by normative values than the general population (Aygun \& Imamoglu, 2002; Schwartz \& Bardi, 2001).

\section{Limitations and Final Conclusions}

Despite the contributions of the present paper to the literature about sojourning, some limitations are important to note. The most important limitation is the fact that we did not provide longitudinal data to disentangle socialization and self-selection effects. However, this limitation does not affect the conclusion of the article, since the main goal was to examine whether intention to sojourn is related to values and personality traits. Further, we used short scales of values and personality that might have impacted the reliability of the scales. As our findings go in the same direction as those documented in the literature (Bardi et al, 2014; Tabor et al., 2015; Zimmermann \& Neyer, 2013), we are confident about the validity of the results reported, but future studies can benefit from using scales with better psychometric indicators.

Overall, our findings offer possible venues for studying abroad advisement and recruitment, pre-departure preparation, or program design by showing the psychological mechanisms related with interests to sojourn. Another line of research could explore further the influence of culture. For example, previous research found that people in Brazil, but also other countries like the UK instantiate excitement (e.g., a varied life) differently (Hanel et al., 2018). Whereas some people instantiate excitement as "seeing the world", others instantiate 
it as "enjoying time with family and friends". We expect that the relation between excitement and sojourning is stronger for the former than the latter group. Finally, future studies should test whether the associations we reported can be replicated with longitudinal designs to provide a more solid understanding of the role of traits and values on interests to sojourn.

Our findings have also applied value. Specifically, they can help to tailor advertisements for exchange programs: Advertisement that is based on people's personality tends to be more effective (e.g., Haddock et al., 2008). For example, our results suggest that people scoring higher on existence values are less keen to go abroad. An advertisement to convince people higher in existence values could emphasis the (institutional) support sojourners are receiving both from their domestic and institution abroad. This is because existence represents a wide range of survival needs and, therefore, safety and personal stability should be imperative for people who score high on this value subfunction.

\section{Conflict of Interest}

On behalf of all authors, the corresponding author states that there is no conflict of interest.

\section{Ethical Approval}

All procedures performed in studies involving human participants were in accordance with the ethical standards of the institutional and/or national research committee and with the 1964 Helsinki declaration and its later amendments or comparable ethical standards.

\section{Informed consent}

Informed consent was obtained from all individual participants included in the study.

\section{Data Availability}

Data and codes are available on osf.io/link will be activated upon acceptance.

\section{References}


Alharbi, E. S., \& Smith, A. P. (2018). Review of the literature on stress and wellbeing of international students in english-speaking countries. International Education Studies, 11(6), 22-44.

Araujo, R. C. R., Bobowik, M., Vilar, R., Liu, J. H., Gil de Zúñiga, H., Kus-Harbord, L., Lebedeva, N., \& Gouveia, V.V. (2020). Human values and ideological beliefs as predictors of attitudes toward immigrants across 20 countries: The country-level moderating role of threat. European Journal of Social Psychology, 50(3), 534-546.

Aygun, Z. K., \& Imamoglu, E. O. (2002). Value domains of Turkish adults and university students. The Journal of Social Psychology, 142(3), 333-351.

Bakalis, S., \& Joiner, T. A. (2004). Participation in tertiary study abroad programs: The role of personality. International Journal of Education Management, 18(5), 286-291.

Bardi, A., Buchanan, K. E., Goodwin, R., Slabu, L., \& Robinson, M. (2014). Value stability and change during self-chosen life transitions: Self-selection versus socialization effects. Journal of Personality and Social Psychology, 106(1), 131-147.

Basow, S. A., \& Gaugler, T. (2017). Predicting adjustment of U.S. college students studying abroad: Beyond the multicultural personality. International Journal of Intercultural Relations, 56, 39-51.

Campbell, P. (2019). Dispositional traits and internal migration: Personality as a predictor of migration in Australia. Journal of Research in Personality, 78, 262-267.

Cleveland, M., Erdogan, S., Arikan, G., \& Poyraz, T. (2011). Cosmopolitanism, individuallevel values and cultural-level values: A cross-cultural study. Journal of Business Research, 64, 934-943.

Costa, P. T., Jr., Terracciano, A., \& McCrae, R. R. (2001). Gender differences in personality traits across cultures: Robust and surprising findings. Journal of Personality and Social Psychology, 81(2), 322-331. 
Czaika, M., \& de Haas, H. (2014). The globalization of migration: Has the world become more migratory? International Migration Review, 48(2), 283-323.

Eyal, T., Sagristano, M. D., Trope, Y., Liberman, N., \& Chaiken, S. (2009). When values matter: Expressing values in behavioral intentions for the near vs. distant future. Journal of Experimental Social Psychology, 45(1), 35-43.

Gallego, A., \& Pardos-Prado, S. (2013). The Big Five Personality Traits and Attitudes towards Immigrants. Journal of Ethnic and Migration Studies, 40(1), 79-99.

Geeraert, N., Li, R., Ward, C., Gelfand, M., \& Demes, K. A. (2019). A tight spot: How personality moderates the impact of social norms on sojourner adaptation. Psychological Science, 30(3), 333-342.

Goldberg, L. R. (1992). The development of markers for the Big-Five factor structure. Psychological Assessment, 4(1), 26-42.

Gosling, S. D. (n.d.). A note on alpha reliability and factor structure in the TIPI. http://gosling.psy.utexas.edu/scales-weve-developed/ten-item-personality-measure-tipi/anote-on-alpha-reliability-and-factor-structure-in-the-tipi/

Gosling, S. D., Rentfrow, P. J., \& Swann Jr., W. B. (2003). A very brief measure of the BigFive personality domains. Journal of Research in Personality, 37(6), 504-528.

Gouveia, V. V. (2003). The motivational nature of human values: Evidences of a new typology [in Portuguese]. Estudos de Psicologia, 8(3), 431-443.

Gouveia, V. V., Albuquerque, F. J. B., Clemente, M., \& Espinosa, P. (2002). Human values and social identities: A study in two collectivistic cultures. International Journal of Psychology, 37(6), 333-342.

Gouveia, V. V., Miltont, T. L., \& Guerra, V. M. (2014). The functional theory of human values: Testing its content and structure hypotheses. Personality and Individidual Differences, 60, 41-47. 
Haddock, G., Maio, G. R., Arnold, K., \& Huskinson, T. (2008). Should persuasion be affective or cognitive? The moderating effects of need for affect and need for cognition. Personality and Social Psychology Bulletin, 34(6), 769-778.

Hanel, P. H. P., \& Maio, G. R. (2020). The Importance of Distinguishing between Semantic Content and Level of Identification in Traits and Values. Preprint. PsyArXiv. https://psyarxiv.com/97bcy

Hanel, P. H. P., Maio, G. R., Soares, A. K. S., Vione, K. C., Coelho, G. L. de H., L, G., ... Manstead, A. S. R. (2018). Cross-cultural differences and similarities in human value instantiation. Frontiers in Psychology, 9.

Henrich, J., Heine, S. J., \& Norenzayan, A. (2010). Most people are not WEIRD. Nature, 466, 29.

Jokela, M. (2009). Personality predicts migration within and between US. states. Journal of Research in Personality, 43(1), 79-83.

Jokela, M. (2014). Personality and the Realization of Migration Desires. In P. J. Rentfrow (Ed.), Geographical Psychology: exploring the interaction of environment and behaviour. Washington D.C: American Psychological Association.

Lechner, C. M., Sortheix, F. M., Obschonka, M., \& Salmela-Aro, K. (2018). What drives future business leaders? How work values and gender shape young adults' entrepreneurial and leadership aspirations. Journal of Vocational Behavior, 107, 57-70.

Maio, G. R. (2010). Mental representations of social values. In M. P. Zanna (Ed.), Advances in Experimental Social Psychology, Vol. 42 (Vol. 42, pp. 1-43). San Diego, CA: Academic Press.

Maio, G. R. (2016). The psychology of human values. Psychology Press.

McCrae, R. R., \& Costa, P. T. (1997). Personality trait structure as a human universal. American Psychologist, 52(5), 509-516. 
Milfont, T. L., Milojev, P., \& Sibley, C. G. (2016). Values stability and change in adulthood: A 3-year longitudinal study of rank-order stability and mean-level differences. Personality and Social Psychology Bulletin, 42(5), 572-588.

Niehoff, E., Petersdotter, L., \& Freund, P. A. (2017). International sojourn experience and personality development: Selection and socialization effects of studying abroad and the Big Five. Personality and Individual Differences, 112, 55-61.

Parks, L., \& Guay, R. P. (2009). Personality, values, and motivation. Personality and Individual Differences, 47(7), 675-684.

Parks-Leduc, L., Feldman, G., \& Bardi, A. (2015). Personality traits and personal values: A meta-analysis. Personality and Social Psychology Review, 19(1), 3-29.

Richter, J., Zimmermann, J., Neyer, F. J., \& Kandler, C. (2020). Do sojourn effects on personality trait changes last? A five-year longitudinal study. European Journal of Personality. doi:10.1002/per.2291

Roccas, S., Sagiv, L., Schwartz, S. H., \& Knafo, A. (2002). The big five personality factors and personal values. Personality and Social Psychology Bulletin, 28(6), 789-801.

Rudnev, M. (2014). Value adaptation among intra-European migrants: Role of country of birth and country of residence. Journal of Cross-Cultural Psychology, 45(10), 1626-1642.

Schwartz, S. H. (1992). Universals in the content and structure of values: Theoretical advances and empirical tests in 20 countries. Advances in Experimental Social Psychology, 25, 1-65.

Schwartz, S. H., \& Bardi, A. (2001). Value hierarchies across cultures taking a similarities perspective. Journal of Cross-Cultural Psychology, 32(3), 268-290.

Szabo, A., Ward, C., \& Jose, P. E. (2016). Uprooting stress, coping, and anxiety: A longitudinal study of international students. International Journal of Stress Management, 23(2), 190-208. 
Tabor, A. S., Milfont, T. L., \& Ward, C. (2015). The migrant personality revisited: Individual differences and international mobility intentions. New Zealand Journal of Psychology, 44, 89-95.

Tartakovsky, E., \& Schwartz, S. H. (2001). Motivation for emigration, values, wellbeing, and identification among young Russian Jews. International Journal of Psychology, 36(2), 88-99.

Tartakovsky, E., Walsh, S. D., Patrakov, E., \& Nikulina, M. (2017). Between two worlds? Value preferences of immigrants compared to local-born populations in the receiving country and in the country of origin. Journal of Cross-Cultural Psychology, 48(6), 835853.

Varela, O. E. (2017). Learning Outcomes of Study-Abroad Programs: A Meta-Analysis. Academy of Management Learning \& Education, 16(4), 531-561.

Yijälä, A., \& Jasinskaja-Lahti, I. (2010). Pre-migration acculturation attitudes among potential ethnic migrants from Russia to Finland. International Journal of Intercultural Relations, 34(4), 326-339.

Zimmermann, J., \& Neyer, F. J. (2013). Do we become a different person when hitting the road? Personality development of sojourners. Journal of Personality and Social Psychology, 105(3), 515.

Zimmermann, J., Schubert, K., Bruder, M., \& Hagemeyer, B. (2017). Why go the extra mile? A longitudinal study on sojourn goals and their impact on sojourners' adaptation. International Journal of Psychology, 52(6), 425-435. 
Table 1

ANCOVAs testing group differences in traits and values.

\begin{tabular}{|c|c|c|c|c|c|}
\hline & \multicolumn{2}{|c|}{$\begin{array}{c}\text { Group } \\
\text { differences }\end{array}$} & \multicolumn{2}{|c|}{ Covariates } & \multirow{2}{*}{$\begin{array}{c}\text { Levene's }{ }^{\mathrm{a}} \\
F\end{array}$} \\
\hline & $F$ & $\eta^{2} p$ & Age & Gender & \\
\hline \multicolumn{6}{|l|}{ Personality } \\
\hline Extraversion & $3.44 *$ & .02 & 2.65 & 2.33 & .30 \\
\hline Agreeableness & $5.09 * *$ & .03 & .10 & $5.31 *$ & .29 \\
\hline Conscientiousness & .84 & .00 & $15.17 * * *$ & 2.14 & .53 \\
\hline Emotional Stability & 1.71 & .01 & $5.66^{*}$ & $17.63 * * *$ & 1.69 \\
\hline Openness & $3.68 *$ & .02 & $4.93^{*}$ & .63 & $4.74 * *$ \\
\hline \multicolumn{6}{|l|}{ Values } \\
\hline Interactive & 1.83 & .01 & $4.28 *$ & $16.74 * * *$ & 2.24 \\
\hline Normative & 2.07 & .01 & $5.08 *$ & $9.32 * *$ & .66 \\
\hline Suprapersonal & 2.61 & .01 & 3.01 & 1.46 & .15 \\
\hline Existence & $3.26^{*}$ & .02 & 1.27 & $12.38 * * *$ & 2.31 \\
\hline Excitement & $6.20 * * *$ & .03 & $12.54 * * *$ & .46 & 2.56 \\
\hline Promotion & 2.49 & .01 & $4.42 *$ & .35 & 1.81 \\
\hline
\end{tabular}


Table 2

Bonferroni post-hoc tests.

\begin{tabular}{|c|c|c|c|c|c|c|}
\hline & $\begin{array}{c}\text { Not keen } \\
\text { vs } \\
\text { Keen } \\
\end{array}$ & $\begin{array}{c}\text { Not keen } \\
\text { vs } \\
\text { Sojourner }\end{array}$ & $\begin{array}{c}\text { Not keen } \\
\text { vs } \\
\text { Ex-Sojourner }\end{array}$ & $\begin{array}{c}\text { Keen } \\
\text { vs } \\
\text { Sojourner }\end{array}$ & $\begin{array}{c}\text { Keen } \\
\text { vs Ex- } \\
\text { Sojourner }\end{array}$ & $\begin{array}{l}\text { Sojourner } \\
\text { vs Ex- } \\
\text { Sojourner }\end{array}$ \\
\hline \multicolumn{7}{|l|}{ Personality } \\
\hline Extraversion & $-1.95(.19)$ & $-2.19(.31)$ & $-3.15 * *(.40)$ & $-0.58(.11)$ & $-1.56(.20)$ & $-0.80(.09)$ \\
\hline Agreeableness & $-0.77(.08)$ & $-3.49 * *(.47)$ & $-1.99(.27)$ & $-3.25 * *(.39)$ & $-1.48(.19)$ & $1.71(.23)$ \\
\hline Openness & $-2.80 *(.26)$ & $-2.65 *(.35)$ & $-2.91 *(.43)$ & $-0.26(.07)$ & $-0.38(.13)$ & $-0.09(.05)$ \\
\hline \multicolumn{7}{|l|}{ Values } \\
\hline Existence & $2.37(.27)$ & $3.00 *(.28)$ & $1.56(.18)$ & $1.09(.01)$ & $-0.72(.11)$ & $-1.62(.12)$ \\
\hline Excitement & $-0.95(.19)$ & $-2.56 \dagger(.37)$ & $-3.74 * *(.53)$ & $-2.00(.17)$ & $-3.31 * *(.31)$ & $-1.01(.11)$ \\
\hline
\end{tabular}


Table S1.

Description of the Big-Five trait dimensions, and Schwartz's and Gouveia's value dimensions.
Big-Five traits
Schwartz's values
Gouveia's Values

\begin{tabular}{|c|c|c|}
\hline \multirow{2}{*}{$\begin{array}{l}\text { Extraversion (1): } \\
\text { Warmth, } \\
\text { gregariousness, } \\
\text { assertiveness, } \\
\text { activity, excitement } \\
\text { seeking, positive } \\
\text { emptions }\end{array}$} & $\begin{array}{l}\text { Power (1): social status and } \\
\text { prestige, control or dominance } \\
\text { over people and resources } \\
\text { Achievement (2): personal success } \\
\text { through demonstrating } \\
\text { competence according to social } \\
\text { standards }\end{array}$ & $\begin{array}{l}\text { Promotion (1): focuses on material } \\
\text { accomplishments and drives } \\
\text { successful social interactions and } \\
\text { assistance to institutional } \\
\text { functioning. Examples are power, } \\
\text { prestige, and success. }\end{array}$ \\
\hline & $\begin{array}{l}\text { Hedonism (3): pleasure and } \\
\text { sensuous gratification for } \\
\text { oneself }\end{array}$ & $\begin{array}{l}\text { Excitement }(2) \text { : focuses on physiological } \\
\text { needs for gratification and it is } \\
\text { conductive to promotion of change, } \\
\text { innovation and non-conformity. } \\
\text { Examples are emotion, pleasure and } \\
\text { sexuality }\end{array}$ \\
\hline $\begin{array}{l}\text { Openness to Experience } \\
\text { (2): Fantasy, } \\
\text { aesthetics, feelings, } \\
\text { actions, ideas, values. }\end{array}$ & $\begin{array}{l}\text { Self-Direction (5): independent } \\
\text { thought and action-choosing, } \\
\text { creating, exploring. } \\
\text { Universalism (6): understanding, } \\
\text { appreciation, tolerance, and } \\
\text { protection for the welfare of all } \\
\text { the people }\end{array}$ & $\begin{array}{l}\text { Suprapersonal (3): represents the high- } \\
\text { order needs of aesthetics, cognition } \\
\text { and self-actualization, emphasizing } \\
\text { more abstract ideas over absolute or } \\
\text { material goals. Examples are } \\
\text { beauty, knowledge, and maturity }\end{array}$ \\
\hline $\begin{array}{l}\text { Agreeableness (3): Trust, } \\
\text { straightforwardness, } \\
\text { altruism, compliance, } \\
\text { modesty, tender- } \\
\text { mindeness. }\end{array}$ & $\begin{array}{l}\text { Benevolence (7): preservation and } \\
\text { enhancement of the welfare of } \\
\text { people with whom one is in } \\
\text { frequent personal contact. }\end{array}$ & $\begin{array}{l}\text { Interactive (4): represents the needs of } \\
\text { belonging, love and affiliation, and } \\
\text { emphasizes social contact as a goal } \\
\text { in itself. Examples are affectivity, } \\
\text { belonging, and social support. }\end{array}$ \\
\hline
\end{tabular}

Tradition (8): respect, commitment, and acceptance of the customs and ideas that traditional and culture or religion provide

Normative (5): focuses on social rules with a materialistic guiding principle, and reflects the importance of preserving one's culture and conventional norms. Competence, order, dutifulness, achievement striving, self-discipline, deliberation.

Conformity (9): restraint of actions, inclinations, and impulses likely to upset or harm others and violate social expectations or norms.

Security (10): Safety, harmony, and stability of society, of relationships, and of the self.
Examples are obedience, religiosity, and tradition.

Existence (6): represents the most basic physiological needs and the need for security. Examples are health, stability, and survival

Emotional Stability (5):

Anxiety, angry

hostility, depression,

self-

conscientiousness,

impulsiveness,

vulnerability.

Note. Similarities between the Big-Five traits and Schwartz' value dimensions are based on metanalysis from Park-Leduc et al. (2015). Similarities between Schwartz's and Gouveia's models of values are based on multidimensional scaling presented by Gouveia et al. (2014b). The content of the descriptions was taken from McCrae \& Costa (1997), Schwartz (1994) and Gouveia et al. (2014). 
Table S2. Descriptive statistics

\begin{tabular}{|c|c|c|c|c|c|c|c|c|c|c|c|c|}
\hline & \multicolumn{3}{|c|}{$\begin{array}{l}\text { Not interested } \\
\text { going abroad } \\
(\mathrm{N}=112)\end{array}$} & \multicolumn{3}{|c|}{$\begin{array}{c}\text { Interested going } \\
\text { abroad } \\
(\mathrm{N}=227)\end{array}$} & \multicolumn{3}{|c|}{$\begin{array}{l}\text { Sojourners } \\
(\mathrm{N}=121)\end{array}$} & \multicolumn{3}{|c|}{$\begin{array}{l}\text { Ex-Sojourners } \\
\qquad(\mathrm{N}=150)\end{array}$} \\
\hline & $\alpha / r$ & $M$ & $S D$ & $\alpha / r$ & $M$ & $S D$ & $\alpha / r$ & $M$ & $S D$ & $\alpha / r$ & $M$ & $S D$ \\
\hline \multicolumn{13}{|l|}{ Values } \\
\hline Interactive & .66 & 5.27 & 1.10 & .59 & 5.31 & 1.00 & .53 & 5.54 & .85 & .39 & 5.45 & .84 \\
\hline Normative & .72 & 4.43 & 1.44 & .69 & 4.37 & 1.39 & .70 & 4.12 & 1.32 & .68 & 4.36 & 1.40 \\
\hline Suprapersonal & .57 & 5.68 & .82 & .48 & 5.82 & .74 & .45 & 5.68 & .73 & .57 & 5.86 & .81 \\
\hline Existence & .44 & 6.14 & .67 & .52 & 5.94 & .79 & .46 & 5.93 & .71 & .44 & 6.02 & .72 \\
\hline Excitement & .50 & 4.77 & .96 & .65 & 4.96 & 1.04 & .35 & 5.13 & .83 & .44 & 5.23 & .89 \\
\hline Promotion & .68 & 4.84 & 1.07 & .60 & 4.97 & 1.04 & .63 & 4.69 & .92 & .64 & 4.90 & .99 \\
\hline \multicolumn{13}{|l|}{ Personality } \\
\hline Extroversion & $.51 * *$ & 3.71 & 1.60 & $.53 * *$ & 4.02 & 1.62 & $.63^{* *}$ & 4.20 & 1.53 & $.56^{*}=$ & 4.33 & 1.59 \\
\hline Agreeableness & .04 & 4.58 & 1.19 & $.14 *$ & 4.67 & 1.18 & .15 & 5.12 & 1.10 & .11 & 4.87 & 1.09 \\
\hline Conscientiousness & .15 & 5.04 & 1.24 & $.31 * *$ & 4.72 & 1.36 & $.24 *$ & 4.93 & 1.29 & $.37 *$ & 4.97 & 1.38 \\
\hline Emotional Stability & $.55 * *$ & 4.10 & 1.57 & $.43 * *$ & 3.76 & 1.52 & $.65 * *$ & 4.08 & 1.68 & $.55^{*}$ & 4.18 & 1.61 \\
\hline Openness & $.31 * *$ & 5.12 & 1.27 & $.35 * *$ & 5.44 & 1.22 & $.23 *$ & 5.52 & .98 & $.23 *$ & 5.57 & 1.10 \\
\hline
\end{tabular}

Note. The reliability for values is the Cronbach`s alpha, but for personality it is the correlation between the two items which compose each trait dimension

Table S3. Correlations between age, gender, values and personality traits for the group with NO interest to study abroad

\begin{tabular}{lllllllllllll}
\hline & 1 & 2 & 3 & 4 & 5 & 6 & 7 & 8 & 9 & 10 & 11 & 12 \\
\hline Age & & & & & & & & & & & & \\
Gender & .013 & & & & & & & & & & \\
Interactive & .040 & $.263^{* *}$ & & & & & & & & & \\
Normative & .041 & .157 & $.498^{* *}$ & & & & & & & & \\
Suprapersonal & .004 & .138 & .185 & $.257^{* *}$ & & & & & & & \\
Existence & .084 & .128 & $.219^{*}$ & $.297^{* *}$ & $.271^{* *}$ & & & & & & & \\
Excitement & $-.249^{* *}$ & .146 & $.204^{*}$ & -.040 & $.244^{* *}$ & .107 & & & & & & \\
Promotion & -.150 & .183 & $.290^{* *}$ & $.192^{*}$ & $.323^{* *}$ & .100 & $.298^{* *}$ & & & & & \\
Extraversion & -.004 & $.219^{*}$ & $.294^{* *}$ & .154 & -.038 & -.048 & .184 & .151 & & & & \\
Agreeableness & .070 & $.201^{*}$ & $.193^{*}$ & .087 & .058 & .030 & -.123 & -.104 & -.105 & & & \\
Conscientiousness & .151 & .089 & $.215^{*}$ & $.218^{*}$ & -.017 & .144 & $-.196^{*}$ & .100 & .105 & .089 & & \\
E. Stability & .148 & .022 & -.042 & -.068 & .021 & -.017 & -.167 & -.026 & $-.204^{*}$ & $.384^{* *}$ & $.191^{*}$ & \\
Openness & .043 & .131 & .046 & -.092 & $.244^{* *}$ & -.128 & .118 & .077 & .151 & .115 & .066 & .092 \\
\hline
\end{tabular}


Table S4. Correlations between age, gender, values and personality traits for the group with interest to study abroad

\begin{tabular}{|c|c|c|c|c|c|c|c|c|c|c|c|c|}
\hline & 1 & 2 & 3 & 4 & 5 & 6 & 7 & 8 & 9 & 10 & 11 & 12 \\
\hline \multicolumn{13}{|l|}{ Age } \\
\hline Gender & -.069 & & & & & & & & & & & \\
\hline Interactive & .119 & $.134^{*}$ & & & & & & & & & & \\
\hline Normative & .114 & $.152^{*}$ & $.298^{* *}$ & & & & & & & & & \\
\hline Suprapersonal & .022 & .019 & $.186^{* * *}$ & $.144^{*}$ & & & & & & & & \\
\hline Existence & -.035 & $.148^{*}$ & $.376^{* *}$ & $.352^{* *}$ & $.331^{* *}$ & & & & & & & \\
\hline Excitement & -.101 & -.100 & $.226^{* *}$ & -.075 & $.230^{* *}$ & $.213^{* *}$ & & & & & & \\
\hline Promotion & -.111 & -.122 & $.189^{* *}$ & .130 & $.285^{* *}$ & $.281^{* *}$ & $.304^{* *}$ & & & & & \\
\hline Extraversion & $.150^{*}$ & -.004 & .124 & .063 & .050 & -.010 & .037 & $.145^{*}$ & & & & \\
\hline Agreeableness & -.087 & .072 & $.166^{*}$ & $.208^{* *}$ & .053 & .019 & -.035 & .019 & .114 & & & \\
\hline Conscientiousness & $.153^{*}$ & .035 & -.003 & $.222^{* *}$ & .042 & $.168^{*}$ & -.074 & .049 & -.005 & .046 & & \\
\hline E. Stability & .103 & 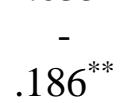 & .049 & $.181^{* *}$ & .051 & .006 & -.091 & .018 & $.189^{* *}$ & $.301^{* *}$ & $.159^{*}$ & \\
\hline Openness & .090 & $-.159^{*}$ & -.012 & -.081 & $.200^{* *}$ & .018 & .096 & $.147^{*}$ & $.327^{* *}$ & .021 & .064 & .097 \\
\hline
\end{tabular}

Table S5. Correlations between age, gender, values and personality traits for the sojourners group

\begin{tabular}{lcccccccccccc} 
& 1 & 2 & 3 & 4 & 5 & 6 & 7 & 8 & 9 & 10 & 11 & 12 \\
\hline Age & & & & & & & & & & & & \\
Gender & -.080 & & & & & & & & & & \\
Interactive & .070 & .139 & & & & & & & & & & \\
Normative & .117 & .024 & $.292^{* *}$ & & & & & & & & & \\
Suprapersonal & $.211^{*}$ & .024 & $.351^{* *}$ & .172 & & & & & & & & \\
Existence & $.195^{*}$ & .148 & $.310^{* *}$ & $.361^{* *}$ & $.312^{* *}$ & & & & & & & \\
Excitement & -.086 & -.062 & $.388^{* *}$ & .080 & $.377^{* *}$ & .053 & & & & & & \\
Promotion & -.078 & - & .047 & .059 & $.316^{* *}$ & .152 & $.371^{* *}$ & & & & & \\
& & $.250^{* *}$ & & & & & & & & & & \\
Extraversion & -.097 & .170 & .144 & $.187^{*}$ & -.061 & .099 & $.272^{* *}$ & .124 & & & & \\
Agreeableness & .107 & .121 & .126 & .044 & .057 & .121 & .055 & -.090 & $.204^{*}$ & & & \\
Conscientiousness & $.242^{*}$ & .041 & .086 & $.294^{* *}$ & $.206^{*}$ & $.279^{* *}$ & .008 & .079 & .124 & $.180^{*}$ & & \\
E. Stability & .087 & -.107 & -.072 & .022 & -.054 & .055 & .028 & .020 & .042 & $.411^{* *}$ & $.207^{*}$ \\
Openness & .065 & .003 & -.049 & .060 & $.456^{* *}$ & .112 & $.303^{* *}$ & .080 & .166 & .154 & $.279^{* *}$ & .027 \\
\hline
\end{tabular}


Table S6. Correlations between age, gender, values and personality traits for the ex-sojourners group

\begin{tabular}{lllllllllllll} 
& 1 & 2 & 3 & 4 & 5 & 6 & 7 & 8 & 9 & 10 & 11 & 12 \\
\hline Age & & & & & & & & & & & & \\
Gender & -.010 & & & & & & & & & & & \\
Interactive & .065 & .142 & & & & & & & & & & \\
Normative & .093 & .114 & $.513^{* *}$ & & & & & & & & & \\
Suprapersonal & .148 & .030 & $.237^{* *}$ & $.189^{*}$ & & & & & & & & \\
Existence & .053 & .150 & $.384^{* *}$ & $.336^{* *}$ & $.347^{* *}$ & & & & & & & \\
Excitement & -.147 & .001 & $.207^{*}$ & .097 & $.181^{*}$ & .057 & & & & & & \\
Promotion & .025 & .130 & $.255^{* *}$ & $.354^{* *}$ & $.372^{* *}$ & $.361^{* *}$ & $.295^{* *}$ & & & & & \\
Extraversion & .100 & -.037 & $.238^{* *}$ & $.207^{*}$ & .067 & -.033 & .113 & .140 & & & & \\
Agreeableness & .049 & .027 & $.173^{*}$ & $.196^{*}$ & -.005 & -.064 & -.116 & -.065 & .061 & & & \\
Conscientiousness & .141 & .079 & .124 & $.205^{*}$ & .154 & $.327^{* *}$ & $-.187^{*}$ & .131 & -.005 & $.202^{*}$ & & \\
E. Stability & .074 & $-.370^{* *}$ & -.095 & -.084 & -.019 & $-.177^{*}$ & -.128 & -.156 & .100 & $.422^{* *}$ & .112 & 1 \\
Openness & $.181^{*}$ & .010 & .155 & .135 & $.224^{* *}$ & -.010 & .108 & .134 & $.250^{* *}$ & $.208^{*}$ & $.305^{* *}$ & .086 \\
\hline
\end{tabular}


Table S7. ANCOVA testing group differences in values using age, gender and traits as covariates.

\begin{tabular}{|c|c|c|c|c|c|c|}
\hline & Interactive & Normative & Suprapersonal & Existence & Excitement & Promotion \\
\hline & $\mathrm{F}\left(\eta^{2} \mathrm{p}\right)$ & $\mathrm{F}\left(\eta^{2} \mathrm{p}\right)$ & $\mathrm{F}\left(\eta^{2} \mathrm{p}\right)$ & $\mathrm{F}\left(\eta^{2} \mathrm{p}\right)$ & $F\left(\eta_{p}^{2}\right)$ & $\mathrm{F}\left(\eta^{2} \mathrm{p}\right)$ \\
\hline Groups & $.69(.00)$ & $3.30(.02)$ & $2.26(.01)$ & $2.68(.01)$ & $5.20(.03)^{* *}$ & $2.27(.01)$ \\
\hline Age & $3.24(.01)$ & $2.30(.00)$ & $1.31(.00)$ & $.25(.00)$ & $12.24(.02)^{* * *}$ & $7.78(.01)^{* *}$ \\
\hline Gender & $8.17(.01)^{* *}$ & $3.58(.01)$ & $1.51(.00)$ & $8.26(.01)^{* *}$ & $.72(.00)$ & $.91(.02)$ \\
\hline Extraversion & $\begin{array}{l}17.78 \\
(.03)^{* * *}\end{array}$ & $11.27(.02)^{* * *}$ & $1.13(.00)$ & $.03(.00)$ & $6.19(.01)^{*}$ & $9.46(.02)^{* *}$ \\
\hline Agreeableness & $\begin{array}{c}16.87 \\
(.03)^{* * *}\end{array}$ & $\begin{array}{c}12.83(.02) \\
* * *\end{array}$ & $.63(.00)$ & $.08(.00)$ & $.27(.00)$ & $1.21(.00)$ \\
\hline Conscientiousness & $2.04(.00)$ & $26.56(.04)^{* * *}$ & $.95(.00)$ & $\begin{array}{c}26.31 \\
(.04)^{* * *}\end{array}$ & $5.32(.01)^{*}$ & $6.03(.01)^{*}$ \\
\hline $\begin{array}{l}\text { Emotional } \\
\text { Stability }\end{array}$ & $4.64(.01)^{*}$ & $1.29(.00)$ & $.30(.00)$ & $1.57(.00)$ & $3.35(.01)$ & $1.38(.00)$ \\
\hline Openness & $.63(.00)$ & $5.04(.01)^{*}$ & $35.98(.06)^{* * *}$ & $.48(.00)$ & $13.49(.02)^{* * *}$ & $5.19(.01)^{*}$ \\
\hline
\end{tabular}

Table S8. Bonferroni post-hoc tests examining group differences in values.

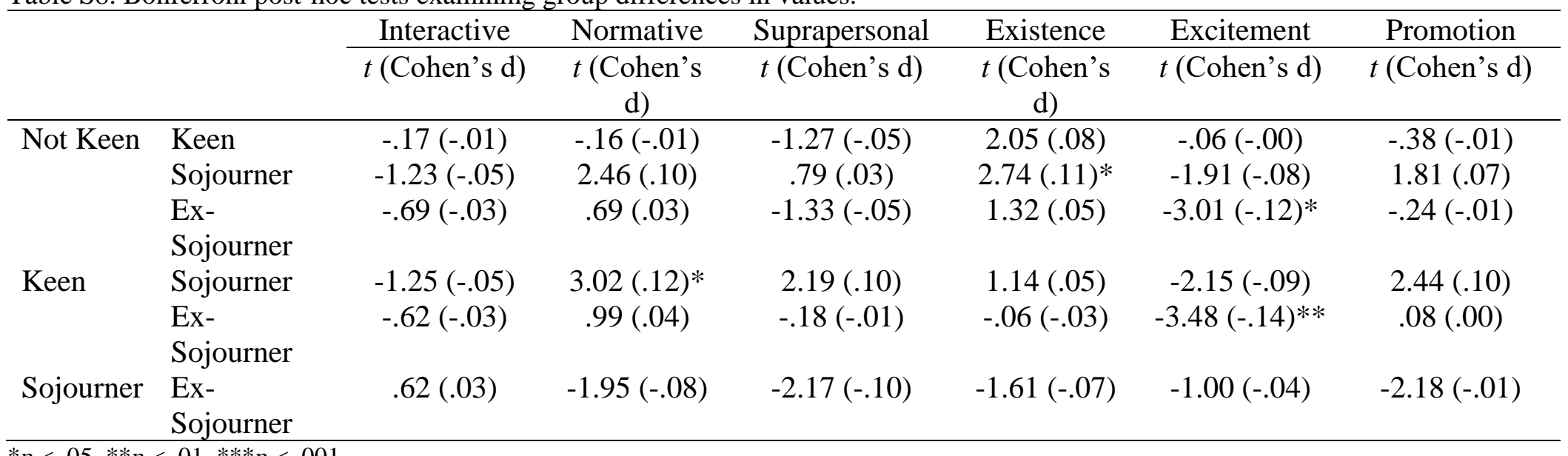


Table S9. ANCOVA testing group differences in traits using age, gender and values as covariates.

\begin{tabular}{|c|c|c|c|c|c|}
\hline & Extraversion & Agreeableness & Conscientiousness & $\begin{array}{l}\text { Emotional } \\
\text { Stability }\end{array}$ & Openness \\
\hline & $F\left(\eta^{2} p\right)$ & $F\left(\eta^{2} p\right)$ & $F\left(\eta^{2} p\right)$ & $F\left(\eta^{2} p\right)$ & $F\left(\eta^{2} p\right)$ \\
\hline Groups & $2.14(.01)$ & $4.74(.02) * *$ & $1.06(.01)$ & $2.18(.01)$ & $2.03(.01)$ \\
\hline Age & $3.78(.01)$ & $.57(.00)$ & $9.77(.02)^{* *}$ & $3.15(.01)$ & $6.25(.01)^{*}$ \\
\hline Gender & $1.67(.00)$ & $1.80(.00)$ & $.25(.00)$ & $18.51(.03) * * *$ & $.24(.00)$ \\
\hline Interactive & $8.67(.01)^{* *}$ & $\begin{array}{c}11.06 \\
(.02)^{* * *}\end{array}$ & $.42(.00)$ & $.01(.00)$ & $.14(.00)$ \\
\hline Normative & $4.73(.01)^{*}$ & $8.32(.01)^{* *}$ & $11.50(.02) * * *$ & $1.46(.00)$ & $.54(.00)$ \\
\hline Suprapersonal & $1.54(.00)$ & $2.34(.00)$ & $.08(.00)$ & $.91(.00)$ & $\begin{array}{c}29.72 \\
(.05) * * *\end{array}$ \\
\hline Existence & $6.74(.01)^{*}$ & $2.52(.00)$ & $12.26(.02) * * *$ & $.51(.00)$ & $4.48(.01)^{*}$ \\
\hline Excitement & $4.47(.01) *$ & $2.17(.00)$ & $9.19(.02)^{* *}$ & $3.59(.01)$ & $4.99(.01)^{*}$ \\
\hline Promotion & $6.99(.01)^{* *}$ & $3.52(.01)$ & $2.86(.00)$ & $.48(.00)$ & $1.41(.00)$ \\
\hline
\end{tabular}

$* p<.05, * * p<.01, * * * p<.001$

Table S10. Bonferroni post-hoc tests examining group differences in traits.

\begin{tabular}{|c|c|c|c|c|c|c|}
\hline & & Extraversion & Agreeableness & Conscientiousness & $\begin{array}{c}\text { Emotional } \\
\text { Stability }\end{array}$ & Openness \\
\hline & & $t$ (Cohen's d) & $t$ (Cohen's d) & $t$ (Cohen's d) & $t$ (Cohen's d) & $t($ Cohen's d) \\
\hline \multirow[t]{3}{*}{ Not Keen } & Keen & $-1.53(-.06)$ & $-.50(-.02)$ & $1.11(.05)$ & $1.49(.06)$ & $-2.05(-.08)$ \\
\hline & Sojourner & $-1.69(-.01)$ & $-3.24(-.13) *$ & $-.34(-.01)$ & $-.13(-.00)$ & $-2.22(-.09)$ \\
\hline & $\begin{array}{l}\text { Ex- } \\
\text { Sojourner }\end{array}$ & $-2.49(-.10)$ & $-1.88(-.08)$ & $-.17(-.01)$ & $-.69(-.03)$ & $-1.93(-.08)$ \\
\hline \multirow[t]{2}{*}{ Keen } & Sojourner & $-.44(-.02)$ & $-3.25(-.13)^{*}$ & $-1.49(-.06)$ & $-1.61(-.07)$ & $-.54(-.02)$ \\
\hline & $\begin{array}{l}\text { Ex- } \\
\text { Sojourner }\end{array}$ & $-1.27(-.05)$ & $-1.67(-.07)$ & $-1.38(-.06)$ & $-2.39(-.10)$ & $-.07(-.00)$ \\
\hline Sojourner & $\begin{array}{l}\text { Ex- } \\
\text { Sojourner }\end{array}$ & $-.68(-.03)$ & $1.59(.01)$ & $.20(.01)$ & $-.55(-.02)$ & $.45(.02)$ \\
\hline
\end{tabular}

$* p<.05, * * p<.01, * * * p<.001$ 


\section{Personality traits and values}
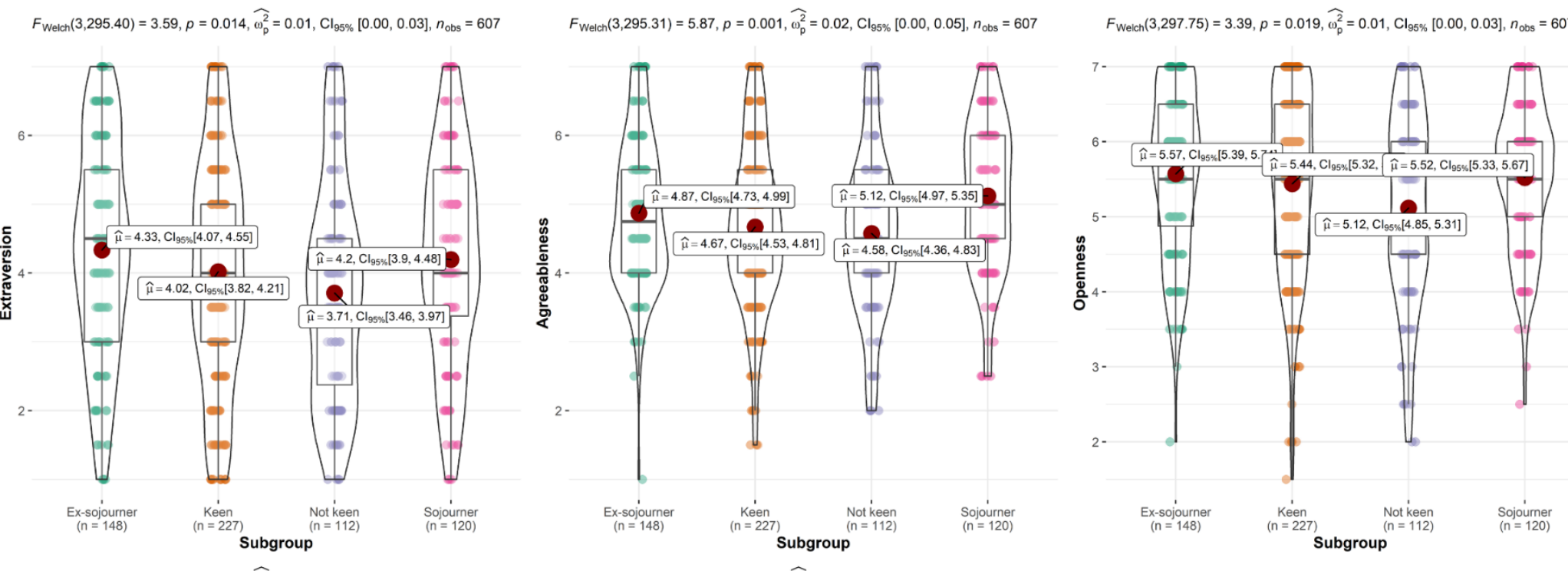

$F_{\text {Welch }}(3,301.53)=2.64, \rho=0.050, \widehat{\omega_{p}^{2}}=0.01, C_{195 \%}[0.00,0.02], n_{\text {obs }}=607$

$F_{\text {Welch }}(3,301.01)=5.96, p=0.001, \widehat{\omega_{p}^{2}}=0.02, C_{95 \% \%}[0.00,0.05], n_{\text {obs }}=607$
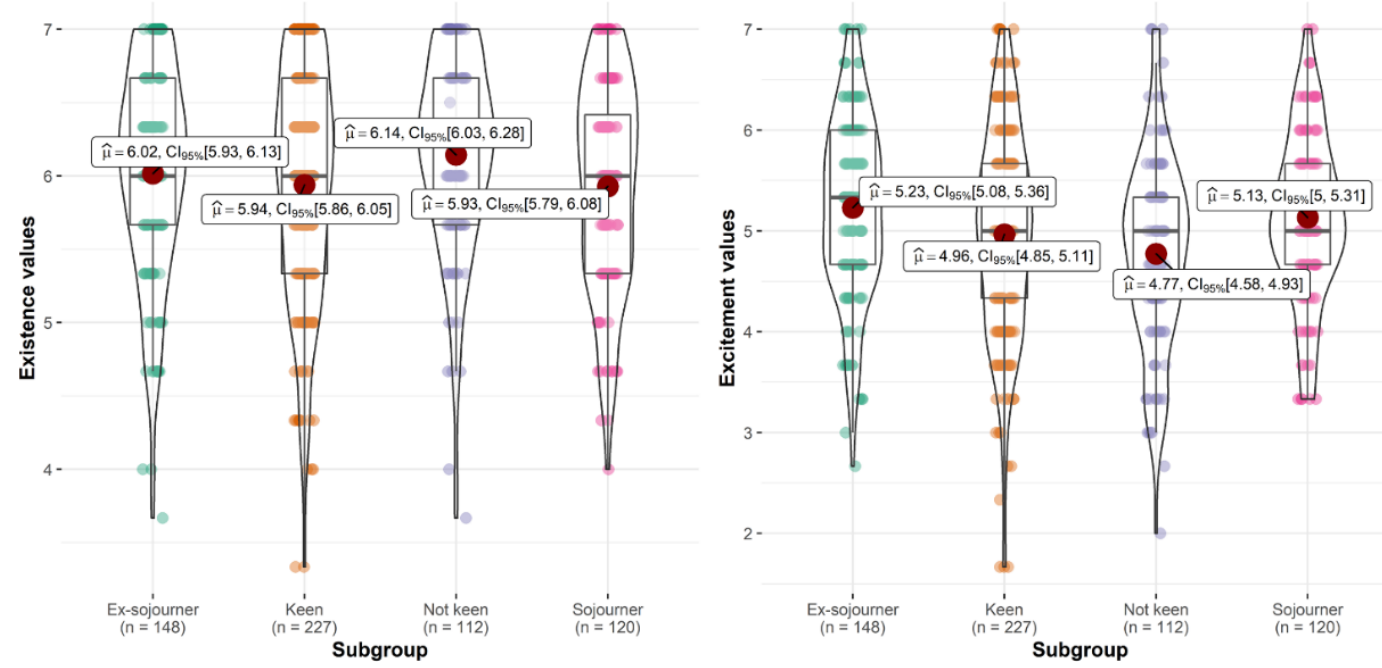